\title{
The Nature of the Relationship between GDP and Energy Consumption in Saudi Arabia
}

\author{
Mohamed Noureldin Sayed ${ }^{1} \&$ Mahmoud M. Hussein Alayis ${ }^{1}$ \\ 1 Assistant Professor, College of Applied Studies and Community Service, Imam Abdulrahman Bin Faisal \\ University, Saudi Arabia \\ Correspondence: Mahmoud M. Hussein Alayis, Assistant Professor, College of Applied Studies and Community \\ Service, Imam Abdulrahman Bin Faisal University, Dammam 31441, Saudi Arabia. E-mail: mmhali@iau.edu.sa
}

Received: February 17, 2019

Accepted: March 28, 2019

Online Published: May 31, 2019

doi:10.5539/ijbm.v14n7p28

URL: https://doi.org/10.5539/ijbm.v14n7p28

\begin{abstract}
This paper aims to explain the relationship between Gross Domestic Product (GDP) and energy consumption in Saudi Arabia; this is one of the most important emerging markets in the Middle East region. Moreover, this paper uses the Granger Causality test, to investigate over the period from 1970 to 2014 the nature of the co-integration between the variables of GDP and energy consumption. This is done to find out the direction of the relationship between GDP and energy consumption in Saudi Arabia. In this regard, we have come to the conclusion that, on the one hand, Saudi Arabia's GDP has no causal effect on the country's energy consumption. However, on the other hand, Saudi Arabia's energy consumption has a causal effect on the country's GDP.
\end{abstract}

Keywords: energy consumption, GDP, Economic Growth, Saudi Arabia, Granger Causality Test

\section{Introduction}

It is posited that the economic development of any country is a leading indicator of the levels and extents of societal economic welfare and the main macroeconomic objectives of any government. The conclusive relationship and the determination of the empirical relationship between other macroeconomic variables, such as consumption, rates of inflation and investment and economic growth, have always been critical for policymakers and that this is an actual topic for consideration in the empirical literature. Those preceding changes in a country's economic composition and structure, which occur as economic development progresses, are typically significant factors that can be used to determine the increasing growth of the demand for energy. With reference to Alkhathlan and Javid's (2013) assessment that, as per the capita income increases, the energy consumption in different sectors, such as transport and construction, is seen to increase relative industrial energy consumption. This rise in energy consumption is driven, also, by the increases in consumer durables and consumer services. Energy helps to stimulate economic development. On a large scale, energy production indicates the level of a country's economic prosperity. Studies maintain that those nations with higher levels of GDP per capita tend consequentially to have high-energy production and consumption levels per capita.

\section{Literature Review}

The terms 'Oil' and 'Saudi Arabia' cannot be decoupled. The country is positioned as the world's leading oil producer and the holder of the second largest oil reserves worldwide. These make Saudi Arabia a leading oil exporter. According to the figures provided by the Saudi Arabian Government, there are estimated to be 260 billion barrels that are widespread near the earth's surface and, thus, make it easier and more profitable to extract them (Alqudair, 2011). The oil sector accounts for typically about 87 percent of Saudi Arabia's budget revenues, 90 percent of export earnings and 42 percent of the nation's GDP (Alkhathla \& Javid, 2013). This production has led to an increase in Saudi Arabians' living standards.

In 2013, the private sector produced 40 percentage of the nation's GDP and employed an estimated 7.5 million foreign workers. Their contribution to Saudi Arabian industries and, more especially, to the service and oil industries played a crucial role in boosting the Saudi Arabian economy (Alqudair, 2011). The Saudi Arabian Government has been trying to enact policies and economic strategies to encourage the growth of the private sector in order to lessen the country's dependence on oil and to increase employment opportunities and to initiate economic growth from within the country's increasing population (Banafea, 2014). Consequently, the Saudi 
Arabian Government has been trying, also, to permit more investments in the private sector and, consequently, acceded to the World Trade Organization's request by allow foreign investments in industries such as telecommunications and power generation (Alkhathla \& Javid, 2013).

During the worldwide high prices of oil that were experienced in the much of the 2000s, the Saudi Arabian Government introduced legislation to record surpluses in the budget and to boost spending on infrastructure development in order to increase the national GDP (Alshehry and Belloumi, 2015). Through these attempts, the collective consumptions of energy have correlated substantially with the levels of economic growth; this varies with the level of energy consumption. With the Saudi Arabian monarchy system of government, there are large-scale supply benefits and the Saudi Arabian economy is seen to be somewhat bewildering from the perspective of other nations (Alqudair, 2011). By combining the country's feudal political patronage systems, the Saudis have gained from individual privileges, obligations and connections. Thus, the fluctuations in Saudi Arabia's GDP correlate to the price of oil and what is happening in the bigger picture. This suggests that Saudi Arabia's fiscal economic growth changes in accordance with the changes in the country's energy consumption (Alshehry and Belloumi, 2015).



Figure 1. Sectorial consumption of energy in Saudi Arabia

With reference to Kuznets' model of economic development and energy consumption, as countries continue becoming wealthier, they interchange between different segments from focusing on agricultural science and growth reliant on resources, into a practice of automation and the connection of the contemporary substructure. Finally, this evolves into a system of consumer-driven development (Kuznets, 1973). Having regard to this conventional view of energy-economic progress relationships, this suggests that as the income rises, initially the energy usage surges steadily before deceleration, summiting and, eventually, undergoing a decline as the process of economic density, affluence and rule move the country's economic structures and advance the production of energy (Alkhathla \& Javid, 2013). In Saudi Arabia, the linear and non-linear incomes and the collective elasticity of prices are essential in the process of estimating the relationships between the development of national income and the rates of energy usage.

The income elasticity of energy demand is typically extraordinary and, both at the national and sectorial levels, upsurges with increases in the national income and GDP, (Banafea, 2014). This backs up the suggestion that, in those nations, such as Saudi Arabia and other nations in the Gulf Corporation Council (GCC), which are in their initial growth and development phases, the consumption of energy always rises with the growth of the economy (Howarth et al., 2017). The growth in both Saudi Arabia's linear and non-linear incomes is reflected significantly in the country's levels of energy consumption. The strong link, which exists between economic development, the rise of national income and the levels of energy consumed in Saudi Arabia, is more likely to be instigated by the changes in the national energy prices which are considerably the lowermost worldwide (Alqudair, 2011). We can conclude that by using the Granger Causality test, this study attempts to analyse the nature of the relationship between GDP and energy consumption and its direction in Saudi Arabia.

\section{Methodology and Data Analysis}

Only the data from 1971 to 2014 could be used due to the lack of available data for the years thereafter. We chose to test Saudi Arabia because it is considered to be the largest country in the world to export oil. In addition, Saudi Arabia owns not only the highest rate of economic growth but it has, also, the largest economy among the 


\section{GCC countries.}

Saudi Arabia's higher per capita income is due considerably to the percentage of oil-based revenue and, more especially, from its exports of oil. The segment of Saudi Arabia's oil-based proceeds and GDP along with the country's growing population demonstrates the variations that exist in the GCC countries concerning their per capita incomes (Alqudair, 2011). The increasing intensity of Saudi Arabia's GDP to energy is different to other economies. In terms of economic development and energy usage, this means that Saudi Arabia has an unusual growth with the correlation between its GDP and energy being instigated by a series of domestic politics and social structures and manufacturing dynamics that traditionally have been controlled by an unusual reliance on oil purchased imports and oil production (Alkhathla \& Javid, 2013).

In 2014, a 1 percent increase in the country's GDP, whether or not in terms of the per capita, induced a 2 percent increase in the energy usage in different economic sectors which varied from the manufacturing to the households (Alshehry and Belloumi, 2015). The transport industry consumed 1.32 percent and the construction industry consumed 1.3 percent. This shows that the impacts, which economic growth and per capita income have on a country, have relative effects on the energy consumption. This relationship is confirmed by the findings of Al-Iriani's (2006) study. This suggests that there exists a unidirectional causality relationship between a country's GDP and its rates of energy consumption.



Figure 2. The rate of energy consumption growth per capita in relation to growth in GDP

The rate of energy consumption has been found to increase with the increase in income in the emerging markets and in the developing economies. In contrast, in those advanced economies, the rate of energy consumption rises with the earnings beyond a point whereby the economy starts to achieve an edged income level (Csereklyei, Rubio \& Stern, 2014). Furthermore, in the non-high revenue economic structures and government regimes especially in the GCC countries, the level of energy consumption rises evidently with the monetary growth (Al-Iriani, 2006). This incidence occurs when the private and local credit facilities are typically used as indicators of fiscal growth. In Saudi Arabia, since the Government has been trying to shift reliance on oil to other sources of income, this indicates a positive trend in the increase of the GDP which will have a significant effect on the level of energy that the country consumes to keep up with the increasing per capita income (Banafea, 2014). Usually, the financial markets undergo developments associated with the national unit of capital flows in the fiscal organizations, the capital marketplaces and the direct foreign investments. In the GCC countries and especially Saudi Arabia, the consumption of energy and changes in the GDP are connected to the usage of energy usage and increase typically at a faster rate than GDP in most segments of the economy with possibly the exception of the transportation industry. Consequently, the rates of GDP growth and energy consumption have been recorded to be rising almost step by step (Howarth et al., 2017).

Saudi Arabia's financial development, achieved through the correlation of national income and energy usage. has had a significant influence on the quality of the environment Presently, at hand are two different outlooks that 
pertain to the influence of the economic developments on the levels of the country's energy consumption. One view argues that the extent of the current developing adeptness of the economic intermediation added to the growing investment prospects can support the rising loans to consumers and firms and, thus, inspire the customers to procure items that are conventionally regarded as being 'large ticket' (Alkhathla \& Javid, 2013). When such items including machinery and automobiles are purchased in large numbers, this increases the level of energy consumption. The second view is from the perspective that in a rising economy, which is boosted by financial investments in different sector other than oil, this is an important aspect in boosting the economy and leads to a consequent increase in the consumption of energy.

As indicated earlier, the Saudi Arabia economy is an oil-centered state and comprises of energy intensive sectors including industries, construction and transport sectors. Therefore, Saudi Arabia's total amount of energy consumption increases rapidly notwithstanding the Government's actions and even guidelines to control the economic expenditures (Burke \& Csereklyei, 2016). According to Saudi Arabia's energy efficiency report by published in January 2011, the rate of the country's energy usage is shown to be developing faster than its GDP. The prime energy usage per capita, which was about 6.8 percent in 2009, has increased and is now four times greater than the worldwide regular consumption (Alkhathla \& Javid, 2013). Using this report's indications and highlights, it can be conceptualized that since 1990 Saudi Arabia's total energy consumption rate has increased at an annual regular rate of 5.8 per hundred since year 1990. Between 1990 and 2009, this rate multiplied by three times. On average between 2000 and 2009, the final and primary energy consumption rates and intensities rose annually by at least 2.3 percent (Alkhathla \& Javid, 2013). Since 2000, the concentration rate of the carbon dioxide has risen, also, annually by 2 percent and this is increasing with the global pollution concerns.

Saudi Arabia's oil exports account for 80 to 90 percent of the country's revenues and more than 40 percent of the GDP. The growth in Saudi Arabia's GDP has been stimulated by the economic thriving economy owing to the historical extraordinary prices and larger subsidies of petroleum. For example, reflecting back to 2008, Saudi Arabia was ranked as the $15^{\text {th }}$ leading user of energy worldwide (Alkhathla \& Javid, 2013). Out of this consumption, 60 percent was oil centered and the others included natural gas. This shows that the country's overreliance on the oil exports as the main source of income generation has to change for a better future and the Government is currently taking proactive steps to ensure such an outcome. Moreover, according to the feedback hypothesis that was developed to explain the causality relationship between GDP and energy usage, this can be used to explain the reason for Saudi Arabia's increasing energy usage (Alqudair, 2011). The feedback proposition is that there is a bi-directional causality between economic development and energy usage. Further, it suggests that the energy preservation policies will have a hostile consequence on the country's commercial productivity whereas an upsurge in commercial productivity will lead to an upsurge in the amount of energy usage. Belaid \& Abderrahmani (2013) developed this proposition and a causative connection is established to exist between Saudi Arabia's economic growth and usage of energy usage.

Distinct from most industrialized nations whereby the GDP development is a function that rises empirically with output and other contributions including occupation, the situation is different in Saudi Arabia. The variability of oil rates is one of the most significant factors in either progressing or weakening the local production. Since, currently, the oil reserves are being exhausted steadily and with no noteworthy innovations to replace them, the oil prices are continually becoming subsidized. With stagnant production, the population growth and the increasing domestic consumption of energy, this means that there will be a decline in per capita income unless the price of oil rises to match the economic growth (Csereklyei, Rubio, \& Stern, 2014). In such a case, the relationship between the Saudi Arabians' per capita incomes will be univariate with regard to the rates of energy consumption. Between 1982 and 2011, the annual rates of Saudi Arabia's total energy usage are increasing progressively at a rate of 7.32 percent. It is critical that the Saudi Arabian Government reviews the current market implications and economic trends in order to come up with effective policies to address the issues of discrepancy between the country's economic growth and the rising rates of energy consumption (Csereklyei, Rubio \& Stern, 2014).

Other types of energy, which are being used increasingly in Saudi Arabia, include electric power. In 2013, the country generated more than 292 billion $\mathrm{Kw} / \mathrm{hr}$. of electricity. The demand for this energy has increased, also, given the increase in population, a rapidly expanding industrial sector, the increase in building construction and heavily subsidized rates of electricity. All obtainable energy producing capability is driven by either natural gas or oil (Howarth et al., 2017). With the growing demand for electricity, the Saudi Arabian Government aims to improve the production of electricity and, typically, this will help to ensure a boost to the economy. An economic boost signifies a positive trend in raising the country's per capita income which, in the long term, will lead to equal levels of energy consumption. Banafea's (2014) research demonstrates that there exists positive and 
significant relationships between a country's rates of energy consumption and, in the long term, its tangible revenue. Nevertheless, in the short term, this connection does not exist. The short and long-term elastic price relationships of energy demand indicate that the use of these energy sources and the prices increases act as effective tool in conserving energy and balancing the elasticity of demand and income (Ibrahim, 2011). Thus, it is arguably notable that the relationship, which exists between a country's rate of economic development and energy usage, has critical policy consequences that intersect with the prospective demand for energy, the economic growth and the rate of climate change. In the GCC, the countries are seeking to meet a common goal of ensuring that they instigate a proper transition so that their economies do not rely as much on oil and gas (Al-Iriani, 2006)

At King Abdullah Petroleum Studies and Research Center (KAPSARC), the topics being investigated include those related to energy effectiveness and the economic growth linked to the theme of energy productivity. To be more precise, KAPSARC research has been investigating different ways of understanding how initiating a shift to a development ideal grounded around complex production can assist the GCC countries to ultimately achieving their long-formulated operational and expansion objectives (Gelil, Howarth, \& Lanza, 2017). Using as an example Saudi Arabia's vision 2030, the energy yield and efficiency is considered to be a programme schema that reflects the concentration on exactly how energy can be better harnessed and used to generate more value for the country. It postulates that efficiency in energy can be utilized, also, to improve the economy significantly significance as well as being a gauge that the Saudi Arabian Government can use to integrate fiscal development with energy usage. At the level of the country's macro-economy, the productivity of energy gives a record description of how GDP can be created by utilizing a specific quantity of energy (Shahateet, 2014). The opposite of energy consumption and how the energy is used for economic purposes and the way it is used for definite undertakings denote the way in which the economy is growing. At the microeconomic level, energy, Saudi Arabia's yield goals focus on the revenue accumulated from the economic undertakings per capita component of energy usage.

Changes in the economic structures, which transpire as progress for commercial growth, are significant features that are used to shape the growing demand for energy (Csereklyei, Rubio \& Stern, 2014). Simultaneously, the economic operational changes can ease a conversion to better financial decisions and the development of a lower contracted base, cleaner activities and extremely polluting undertakings that deliver, also, employment opportunities and higher per capita income (Alqudair, 2011). This relationship is well documented in accordance with Kuznets' previously mentioned theory. The energy economists continue to show some long-standing interests in the elasticity between GDP and energy contained in aggregate energy demand readings. Using these indicators, if the elasticity falls lower than one, then, the aggregate energy expenditure will rise typically at a measured rate other than the GDP (Mehrara, 2007). For countries like Saudi Arabia, it is extremely vital to achieve an energy-GDP elasticity of below one. This is because; the concentrated local consumption of energy liberates amounts of capital that are supposed to be expected and traded overseas and, thus, improves the country's energy yield.

In Saudi Arabia, the KAPSARC examination on energy efficiency uses the general equilibrium model which suggests that a national economy-wide improvement in the energy efficiency of around 4 percent per year could result empirically in around 1 million oil barrels or equivalent being avoided by 2030 (Gelil, Howarth, \& Lanza, 2017). If this oil is exported in the international markets and the return is re-invested back into the economy, this could generate more income ranging to about SAR 100 billion extra revenue per year by 2030 (Alshehry and Belloumi, 2015). Subject to the international energy market environments, and reinvestment back into the economy, research finds that this could increase Saudi Arabia's GDP growth by between 0.3 and 0.6 percent per year.

The Granger Causality Test was performed by using the E. views 9 software package to calculate in the period from 1971 to 2014 the correlation coefficient between Saudi Arabia's GDP (current LCU) and energy consumption per capita. As shown in Table 1, the same test was used to find a causal relationship between the two variables during the same period. 
Table 1. Granger causality test

\begin{tabular}{lccl}
\hline Pairwise Granger Causality Tests & & & \\
\hline Sample: $1971-2014$ & & & \\
Lags: 2 & Obs & F-Statistic & Prob. \\
Null Hypothesis: & 41 & 1.67143 & 0.2022 \\
\hline DLG does not Granger Cause DLE & & 2.51658 & 0.0948 \\
\hline DLE does not Granger Cause DLG
\end{tabular}

As shown by either the value of the calculated $\mathrm{F}$ test or by the value of the $\mathrm{P}$ value level at a significant level of $10 \%$, this is more than $10 \%$ in the initial case, This led to the acceptance of the null hypothesis that the GDP does not affect the energy consumption per capita. As for the second case, there is acceptance of the alternative hypothesis where the $\mathrm{P}$ Value is less than $10 \%$; this means that the energy consumption per capita affects the GDP.

We conclude from the above that, on the one hand, GDP has no causal effect on energy consumption per capita. On the other hand, energy consumption per capita has a causal effect on GDP. Researchers faced difficulty in accessing from the energy consumption per capita index data for the period from 2015 to 2018 . This led to the exclusion of these years from the causal analysis of the variables.

\section{Conclusion}

Accordingly, in relation to Kuznets theory of energy consumption and economic development, it is thus relatively evident that, as countries continue to grow richer, the economic growth relates directly related to the rates of energy consumption. The strong linkage between Saudi Arabia's level of economic growth and energy usage is expected to be determined by the low rates of national energy. In order to meet its 2030 vision, Saudi Arabia will need to balance growth and energy consumption. When the country's economy continues to grow, this will have an equal effect on the amount of consumed energy. Balancing the growth and development by using fiscal policies and creating room for more investments will allow Saudi Arabia to harness other sources of energy such as electricity to reduce its oil consumption. An economic boost signifies a positive trend in raising the country's per capita income and, in the long term, this will lead to equal levels of energy consumption. In addition, by using the Granger Causality test, we discovered the nature and direction of the relationship between Saudi Arabia's economic growth and energy consumption.

\section{Limitations and Suggestions for Future Research}

The discoveries of this investigation is the nature of the relationship between GDP and Energy Consumption in Saudi Arabia by using the Granger Causality test. It contrasts from past investigations in that it looks at the direction of the relationship between GDP and energy consumption, because of the curiosity of this field of study, it has certain limitation over the period 1971 till 2014.

The further studies could contains a comparative study of the Gulf Countries with a similar nature in income and energy consumption to reach the nature of the relationship in those countries. As well as the possibility of using more accurate statistical methods in examining the nature of that relationship and through more information for longer periods.

\section{References}

Al-Iriani, M. A. (2006). Energy-GDP relationship revisited: an example from GCC countries using panel causality. Energy policy, 34(17), 3342-3350. https://doi.org/10.1016/j.enpol.2005.07.005

Alkhathlan, K., \& Javid, M. (2013). Energy consumption, carbon emissions and economic growth in Saudi Arabia: An aggregate and disaggregate analysis. Energy Policy, 62, 1525-1532. https://doi.org/10.1016/j.enpol.2013.07.068

Alqudair, K. H. (2011). Causal relationship between energy consumption and economic growth in the Kingdom of Saudi Arabia. The Journal of Energy and Development, 37(1/2), 129-142. https://www.jstor.org/stable/24812734

Alshehry, A. S., \& Belloumi, M. (2015). Energy consumption, carbon dioxide emissions and economic growth: The case of Saudi Arabia. Renewable and Sustainable Energy Reviews, 41, 237-247. https://doi.org/10.1016/j.rser.2014.08.004

Banafea, W. A. (2014). Structural breaks and causality relationship between economic growth and energy 
consumption in Saudi Arabia. International Journal of Energy Economics and Policy, 4(4), 726-734. http://www.econjournals.com/index.php/ijeep/article/view/934

Bélaïd, F., \& Abderrahmani, F. (2013). Electricity consumption and economic growth in Algeria: A multivariate causality analysis in the presence of structural change. Energy Policy, 55, 286-295. https://doi.org/10.1016/j.enpol.2012.12.004

Burke, P. J., \& Csereklyei, Z. (2016). Understanding the energy-GDP elasticity: A sectoral approach. Energy Economics, 58, 199-210. https://doi.org/10.1016/j.eneco.2016.07.004

Csereklyei, Z., Rubio, M., \& Stern, D. I. (2014). Energy and economic growth: The stylized facts. https://dx.doi.org/10.2139/ssrn.2734493

Gelil, I., Howarth, N., \& Lanza, A. (2017). Growth, investment and the low carbon transition: A view from Saudi Arabia. KAPSARC Discussion Paper.

Howarth, N., Galeotti, M., Lanza, A., \& Dubey, K. (2017). Economic development and energy consumption in the GCC: an international sectoral analysis. Energy Transitions, $1(2), 6$. https://link.springer.com/article/10.1007/s41825-017-0006-3\#citeas

Ibrahim, M. (2011). Energy consumption, income and price interactions in Saudi Arabian economy: a vector autoregression analysis. Advances in Management \& Applied Economics, 1(2), 1-21. https://dx.doi.org/10.2139/ssrn.2359746

Kingdom of Saudi Arabia: vision 2030. Retrieved from http://vision2030.gov.sa/en. (2017)

Kuznets, S. S. (1971). Economic growth of nations. Retrieved from http://www.nal.usda.gov/

Mehrara, M. (2007). Energy consumption and economic growth: the case of oil exporting countries. Energy Policy, 35(5), 2939-2945. https://doi.org/10.1016/j.enpol.2006.10.018

Shahateet, M. I. (2014). Modeling economic growth and energy consumption in Arab countries: Cointegration and causality analysis. International Journal of Energy Economics and Policy, 4(3), 349-359. Retrieved from http://econjournals.com/index.php/ijeep/article/view/818

\section{Appendix}

Appendix 1. The growth rate of Saudi Arabia's GDP and energy consumption

\begin{tabular}{|c|c|c|c|c|}
\hline Year & GDP Growth & GDP & Energy Consumption per & Energy Consumption Growth \\
\hline 1971 & 20.51222 & 718485334 & 1206.048064 & - \\
\hline 1972 & 22.93064 & 966415749 & 977.617552 & -18.94041527 \\
\hline 1973 & 24.17053 & 149473911 & 1077.265514 & 10.19293911 \\
\hline 1974 & 16.22807 & 454129577 & 1146.43676 & 6.421002573 \\
\hline 1975 & -8.92861 & 467733682 & 1180.410632 & 2.963431789 \\
\hline 1976 & 17.82097 & 640056657 & 1300.452906 & 10.16953521 \\
\hline 1977 & 7.09336 & 741882499 & 1379.557253 & 6.082830524 \\
\hline 1978 & -5.21973 & 802656194 & 1967.691686 & 42.63211488 \\
\hline 1979 & 11.91943 & $1.1186 \mathrm{E}+11$ & 2445.598244 & 24.28767485 \\
\hline 1980 & 5.652458 & $1.64542 \mathrm{E}+1$ & 3192.868529 & 30.55572543 \\
\hline 1981 & 1.943004 & $1.84292 \mathrm{E}+1$ & 4081.19297 & 27.8221428 \\
\hline 1982 & -20.7299 & $1.53239 \mathrm{E}+1$ & 4291.356507 & 5.149561373 \\
\hline 1983 & -16.0514 & $1.29172 \mathrm{E}+1$ & 4406.54074 & 2.684098436 \\
\hline 1984 & -4.66145 & $1.19625 \mathrm{E}+1$ & 3660.761618 & -16.92436688 \\
\hline 1985 & -9.7945 & $1.03898 \mathrm{E}+1$ & 3487.24088 & -4.740017416 \\
\hline 1986 & 17.01275 & 869619227 & 3312.823221 & -5.001594828 \\
\hline 1987 & -6.6325 & 856958611 & 3781.046644 & 14.13366765 \\
\hline 1988 & 13.10931 & 882560747 & 4148.768118 & 9.725388444 \\
\hline 1989 & -0.50302 & 953444592 & 3990.986005 & -3.803107531 \\
\hline 1990 & 15.19343 & $1.1763 \mathrm{E}+11$ & 3552.714292 & -10.9815397 \\
\hline 1991 & 15.00788 & $1.32223 \mathrm{E}+1$ & 4002.95201 & 12.67306292 \\
\hline 1992 & 3.98754 & $1.37088 \mathrm{E}+1$ & 4426.463906 & 10.57998934 \\
\hline 1993 & -1.36374 & $1.32968 \mathrm{E}+1$ & 4471.446073 & 1.016209959 \\
\hline 1994 & 0.55872 & $1.35175 \mathrm{E}+1$ & 4588.954344 & 2.62797022 \\
\hline 1995 & 0.212091 & $1.43343 \mathrm{E}+1$ & 4510.416639 & -1.711450992 \\
\hline
\end{tabular}




\begin{tabular}{lllll}
\hline $\mathbf{1 9 9 6}$ & 2.637424 & $1.58662 \mathrm{E}+1$ & 4728.228168 & 4.829077801 \\
$\mathbf{1 9 9 7}$ & 1.103782 & $1.65964 \mathrm{E}+1$ & 4422.53651 & -6.465247608 \\
$\mathbf{1 9 9 8}$ & 2.893363 & $1.46775 \mathrm{E}+1$ & 4623.704474 & 4.548701035 \\
$\mathbf{1 9 9 9}$ & -3.76329 & $1.61717 \mathrm{E}+1$ & 4611.619773 & -0.261364025 \\
$\mathbf{2 0 0 0}$ & 5.625416 & $1.89515 \mathrm{E}+1$ & 4712.743673 & 2.192806528 \\
$\mathbf{2 0 0 1}$ & -1.21074 & $1.84137 \mathrm{E}+1$ & 4715.132077 & 0.0506797 \\
$\mathbf{2 0 0 2}$ & -2.81917 & $1.89606 \mathrm{E}+1$ & 5078.498896 & 7.706397469 \\
$\mathbf{2 0 0 3}$ & 11.24206 & $2.15808 \mathrm{E}+1$ & 4990.770124 & -1.727454782 \\
$\mathbf{2 0 0 4}$ & 7.958442 & $2.58742 \mathrm{E}+1$ & 5157.480362 & 3.340370992 \\
$\mathbf{2 0 0 5}$ & 5.57385 & $3.2846 \mathrm{E}+11$ & 5126.341367 & -0.603763714 \\
$\mathbf{2 0 0 6}$ & 2.788402 & $3.769 \mathrm{E}+11$ & 5525.01843 & 7.777029163 \\
$\mathbf{2 0 0 7}$ & 1.84713 & $4.15965 \mathrm{E}+1$ & 5556.713378 & 0.573662312 \\
$\mathbf{2 0 0 8}$ & 6.249773 & $5.19797 \mathrm{E}+1$ & 6034.523262 & 8.59878585 \\
$\mathbf{2 0 0 9}$ & -2.05927 & $4.29098 \mathrm{E}+1$ & 6250.328114 & 3.576170681 \\
$\mathbf{2 0 1 0}$ & 5.039494 & $5.28207 \mathrm{E}+1$ & 6763.336882 & 8.207709401 \\
$\mathbf{2 0 1 1}$ & 9.996858 & $6.71239 \mathrm{E}+1$ & 6307.892055 & -6.734025453 \\
$\mathbf{2 0 1 2}$ & 5.411445 & $7.35975 \mathrm{E}+1$ & 6888.066388 & 9.197594508 \\
$\mathbf{2 0 1 3}$ & 2.699255 & $7.46647 \mathrm{E}+1$ & 6417.917148 & -6.825561976 \\
$\mathbf{2 0 1 4}$ & 3.652482 & $7.5635 \mathrm{E}+11$ & 6937.230677 & 8.091620965 \\
\hline
\end{tabular}

\section{Copyrights}

Copyright for this article is retained by the author(s), with first publication rights granted to the journal.

This is an open-access article distributed under the terms and conditions of the Creative Commons Attribution license (http://creativecommons.org/licenses/by/4.0/). 